\title{
The National Health Service at a Critical Moment: when Brexit means Hectic
}

\author{
JOAN COSTA-FONT \\ Department of Health Policy \& European Institute, London School of Economics and Political \\ Science (LSE), Houghton Street, London WC2A 2AE, United Kingdom. \\ e-mail: j.costa-font@/se.ac.uk
}

\begin{abstract}
Leaving the European Union (so-called 'Brexit') is a 'critical moment' for health policy reform which can pave the way to different pathways, including, a 'critical juncture'. Given that Brexit cannot be undone without a second referendum, it opens up opportunities to elude European constraints for reform along the lines of equity, employment rights and patient choice. Brexit deepens the financial crisis of the National Health Service (NHS) by increasing hiring costs and imposing new transaction costs to accommodate patient cross-border mobility and international public health needs. Given the weak sustainability of the NHS, it could lead to major system reform.
\end{abstract}

\section{Introduction}

Health care and the National Health Service (NHS) budget were intrinsically associated with the Brexit referendum narrative. During the referendum, the slogan used by the 'leave campaign' to garner support for their cause weighed heavily on the significant savings Brexit would bring from not contributing to the EU budget. The assumption was that they could rather be invested in the NHS (and estimated to amount to the much mentioned ' $\mathfrak{E} 350$ million a week savings'). However, by the time the outcome of the referendum was announced, most of those 'implicit promises' had already vanished, and it became evident that health care underfunding had very little to do with the European Union. This paper examines the most immediate implications of Brexit for healthcare, and how exit from both the European Union and the Single Market will affect the future of the NHS.

In examining the consequences of Brexit, one ought to factor in the weak financial sustainability of the NHS. According to estimates from the King's Fund, in 2015-16 the NHS had the largest deficit in its history. NHS funding has been unable to keep pace with a growing demand for services, especially given the near absence of expenditure increases. This is concerning given that quality shortcomings can be associated with limited staff availability. Evidence of 
resource-driven failures of care, such as the case of the Mid-Staffordshire NHS Foundation Trust, are still very recent (Dunn et al., 2016) and stand out as a paradigmatic example of how resource constraints can put health services under strain. For instance, the availability of community nurses in England has sharply declined by about 19 per cent over the last decade in England (Addicott et al., 2015), despite the expanded workloads.

The common reaction to such staff shortages has traditionally been a higher reliance on private temporary contract agencies to fill workforce gaps and, more generally, on private providers who already make up 18 per cent of NHS spending on community health services (Lafond et al., 2014). Given the time needed to train new nurses, these pressures create an average nursing vacancy rate of 15-20 per cent in community health services (Foot et al., 2014). In that scenario, the most obvious choice is to hire internationally, and especially from EU countries. However, leaving the European Union in such a context creates a conundrum for English hospitals regarding how to square their objectives on 'quality' and 'cost': any extra quality inevitably entails extra resources which are not available without extra funding. Hence, Brexit raises questions about the financial sustainability of an unreformed NHS; that is, an NHS without extra funding and attempting to maintain quality standards.

In what follows, we examine the expected effects of Brexit on the NHS, in a generic way, without detailed information on the exact terms of the final deal. At the time of writing the article, precise estimates would require making a number of unreasonable assumptions about the effect of leaving the European Union; hence we mainly focus on the potential institutional consequences instead. This paper will concentrate on identifying and discussing some of the main issues that Brexit brings to the organisation of the NHS. I will focus on its effects on worker and patient mobility. I will argue that leaving the EU entails an unparalleled both institutional and economic shock that gives rise to a 'critical moment' for policy reform given the weak financial position (fiscal deficit) of the NHS. Specifically, leaving the EU will entail a rise in hiring costs and will impose new transaction costs to accommodate both patient cross-border mobility and international public health needs.

I further argue that the outcome of such a critical moment opens several possible scenarios, some of which may involve a progressive process of substitution of EU for non-EU staff, and adjustments to the potential shortages in NHS funding. In some extreme circumstances, it may give rise to a 'critical juncture' (Capoccia and Kelemen, 2007; Greer, 2009).

Nonetheless, for a critical juncture to take place, Brexit would have to shift the preferences of sectors of the electorate (middle class) and political agents towards a widespread system reform and further privatisation in the financing of health care services (e.g. private health insurance uptake). This includes a heavier reliance on private agency providers to counteract the shortages in NHS health 
care staff. However, the extent to which the fiscal consolidation of the NHS takes policy priority (over injecting funds to maintain quality standards) at this 'critical moment' is crucial for a critical juncture to unfold. Brexit is estimated to lead to a reduction of 6.3-9.5 per cent of national income (Van Reenen, 2016) ${ }^{1}$, and one can expect expenditure cuts if fiscal sustainability goals are maintained. Alternatively, if further health care investment is prioritised after Brexit, it is unlikely that a critical juncture will take place, and instead a more moderate transformation in the functioning of the NHS should be expected.

The rest of the paper will be devoted to substantiating these arguments. The paper is as follows. Next, we will discuss the costs of Brexit on the NHS, followed by the effect of EU governance on the health system. We will then look at the effect Brexit has on the mobility of health and social care workers, and also of patients. Finally, the paper will conclude with a discussion section that summarizes the main policy implications and opportunities.

\section{Brexit and its costs to the NHS}

After Brexit, the UK might save a contribution to the EU funds, but estimates indicate at most a net saving of 0.31 per cent of national income ( 0.53 per cent of fiscal transfer minus 0.22 per cent, namely the contribution of the EU to business, universities and other bodies). However, even such a benefit will dissipate if Britain, as it is expected, is required to pay a contribution to access some aspects of the single market (Van Reenen, 2016). The latter includes speedy access to key health technologies and, most importantly, cross-border care that both EU nationals in the UK and UK nationals in the EU receive ${ }^{2}$.

The effects of Brexit on the NHS will be more critical in the management of human resources, procurement and patient care. Retention and hiring of EU health professionals will be more challenging both on pay and on social integration of European staff ${ }^{3}$. Leaving the EU entails the introduction of important restrictions on labour mobility which can shift labour costs upwards (e.g. higher medical fees will be required to incentivise a declining medical work force and vacancies might increasingly need to be covered by temporary staff). In addition, one can expect higher transaction costs to purchase intermediary goods (e.g. medicines and medical devices) when we lose access to the single market which, in turn, may force the NHS to adopt tighter budgets on both medical research and health services (Mossialos et al, 2016). Part of the latter results from increased transaction costs from potential new tariffs, and especially non-tariff barriers, once single market regulations become non-binding to the UK.

On the patient's side, the UK may lose out significantly after Brexit too. The balance of payments associated with free patient mobility seems to have traditionally benefited the UK, given that British expats tend, overall, to be older 
than EU residents in the UK: who are on average younger, healthier and more highly skilled. Specific attention will have to be focused on the large share of British pensioners in some EU countries such as Spain and France (McKee and Galsworthy, 2016). Hence, any change in those terms would be expected to add additional pressures to the already weak financial position of the NHS.

\section{Brexit and health system governance}

In evaluating the effects of Brexit on health care governance, it is important to keep in mind that a pre-Brexit Cabinet Office document defined the balance of competence on health policy between the EU and the UK as 'broadly appropriate' (Cabinet Office, 2013). Hence, Brexit entails departing from such a 'balanced scenario'.

From a legal perspective, the European Union plays a modest role in health policy (as it primarily acts as a 'regulatory state'). Article 168(7) of the Treaty of the EU assigns to member states the responsibility for health policy, management of health services and the allocation of medical resources. However, progressively, the EU has become a more important actor in a number of health care areas including cross-border healthcare, tobacco and alcohol, AIDS and cancer, health information, organs and blood donation as well as intermediate goods subject to internal market regulation. The latter (e.g. medicines, medical devices) are scrutinised by the European Court of Justice (ECJ) alongside the regulation of health professionals. All these areas are hence directly affected by Brexit. However, indirectly, a number of other areas are also impacted. Single market legislation has directly affected both public procurement and provided unified new medicine licenses and labour market regulations such as the Working Time Directive (WTD). Treaty articles have legislated on mutual recognition of training and have been active in limiting the capacity of governments to discriminate in favour of domestic suppliers and keep the labour market open to competition. However, the direct EU effects on governance have been more limited and mainly operate through 'soft governance', namely the socalled 'open methods of coordination' (OMC) ${ }^{4}$ and recently European Semester policies ${ }^{5}$.

Health care reform in the UK over the last decades has focused primarily on developing internal provider choice and competition policies much in line with European single market principles. However, fiscal consolidation has been a pressing matter for a long time. Tony Blair's governments addressed the chronic problem of underfunding by injecting funds into the system and committed to raise spending to the EU average. Europe was used as a benchmark to raise health care investment. Furthermore, the European Commission has played a fairly active role both by coordinating the exchange of good practices (e.g. using health care targets referring to the attainment of healthy life-years alongside 
the provision of long-term care), and by adopting some fiscal surveillance mechanisms in the content of the European Semester (Azzopardi-Muscat et al., 2015). Finally, leaving the EU may potentially loosen the influences that have made it possible for the UK to implement desirable policies by overcoming lobbies and other obstacles. ${ }^{6}$

Other sources prompting the Europeanisation of health policy include the adoption of the European Charter of Fundamental Rights that recognises the right to both curative and preventive care (article 35), and the 2006 European Council statement of overarching values of universality, access to good-quality care, equity and solidarity. The Lisbon Treaty in 2007 strengthened the EU role on health, and the EC Health Strategy 2008-2013 (European Commission, 2007) states a commitment to reducing inequities in health, promoting 'health literacy' and, especially, including 'health' as a policy objective in other policies such as poverty reduction. Consistently, the health programme 2014-2020 reiterates the values of equity and solidarity and the goal of reducing health inequalities. Hence, reducing its effects on Britain can have consequences.

\section{Brexit and the health economy}

\section{Staff recruitment}

The UK has a long history of being a recruiter of internationally educated health professionals that have helped sustain the NHS (Aiken and Buchan, 2004). Since the implementation of Regulation 1408/71 in 1971, establishing the portability of social security rights for employees moving across borders, the European Commission has promoted the setting up of a so-called 'European health professionals space'. As stated by the Royal College of Nursing (2017), common standards on training and recognition of qualifications have facilitated European recruitment. Conversely, changes to those regulations are likely to give rise to new legal and administration costs which will make such recruitment more costly.

Although the UK has been an EU member since 1973, the inflow of EU health professionals to the UK significantly expanded after 2004. This was due to the accession of eastern European countries and, especially, to the implementation of some key regulations (e.g. education and training standardisation to enable automatic registration in another EU country, and EU Directive 2005/36/EC which allows temporary work entitlements to health professionals). Given that both coincided with a significant reduction in the numbers of trainees, this inflow helped to cope with the local undersupply of health professionals. Indeed, the considerably lower wages in the countries of origin of EU migrants accessing the UK after 2004 led to NHS recruitment agencies attracting a significant number of professionals (Ballard and Laurence 2004; Blitz, 2005), saving the UK taxpayer the costs of training such staff. 
However, even with such an inflow of EU professionals, the NHS has struggled to recruit and retain permanent staff. In 2014, there was a shortfall of 5.9 per cent, and in social care 5.4 per cent, rising to 7.7 per cent in domiciliary care services (King's Fund, 2016), and about one-third of all UK nurses are due to retire in the next ten years (Royal College of Nursing, 2017). The problem is more alarming when one looks at the GP workforce (Buchan et al., 2016). A recent report of the Royal College of Physicians (2017) suggests that, in 2016, 86 per cent of physicians experienced shortages across clinical teams. According to the English Health Service's Electronic Staff Record (2016), there were around 144,000 EU nationals working in health and social care organisations across England in 2016 of which 57,063 worked in health care in the NHS; and 6,209 worked in independent health organisations providing infrastructure support. The EU nationals' workforce is made up of 38,883 clinical staff; 10,136 doctors; 20,711 nurses; 11,732 clinical support staff and 1,336 midwives. Overall, EU immigrants make up about 5 per cent of English NHS staff (and about the same percentage of the English population, according to the best available data. Across the UK, EU immigrants make up 9 per cent of registered doctors and 4 per cent of registered nurses. However, such percentages are much higher when one looks at specific specialised consultants.

The research so far has been able to identify some different patterns of EU staff by country of origin. Baker (2016) distinguishes EU staff by nationality and finds that a third of the staff from 'old' EU countries are Irish and 72 per cent of EU staff in the NHS are women. Importantly, when the data disaggregates between old (pre-2004) members and new member states ('A8' East European countries), one finds an increase from 2.2 per cent to 3.8 per cent between 2009 and 2016 for the former, and a smaller increase from 0.7 per cent to 1.5 per cent for the latter ${ }^{7}$. Of the staff that recently joined in 201516, 13 per cent were from other EU countries while, for nurses, the figure was 18 per cent. This suggests that accession did not affect the NHS as it did other sectors of the economy, but that EU staff make up an increasing share of new hires. In particular, the inflow of nurses has increased in recent years, notably from European Union (EU) countries, in response to recruitment difficulties.

Another important driver of staff expansion is local policy dynamics and, specifically, concerns over quality in English hospitals after the publication of the Francis Report (2013) which identified a link between shortages and poor quality of care. The latter led to an increase in the demand for nurses. However, back in 2015, 93 per cent of NHS trusts in England reported registered nurse shortages (NHS Employers, 2015) and estimates point out that recent staff increases in 2015/16 and 2016/17 are unlikely to alleviate the immediate and short-term needs and the NHS will be required to rely on nurses trained in the EU or overseas. 


\section{Counterfactuals}

To understand the impact of Brexit one can look for potential counterfactuals. One example can be found in the 2010 restrictions on hiring non-EU immigrants which had a significant influence on NHS recruitment, mostly bringing about transaction costs (e.g. legal restrictions) on the hiring of health professionals ${ }^{8}$. For instance, Baker (2016) finds a reduction of 37 per cent in the number of Indian doctors working in the UK from 2009 to 2016 due to such restrictions. However, to such legal restrictions one could add wider 'social restraints', namely individuals being discouraged from coming to Britain due to a change in the working environment after Brexit (e.g. migrants 'othering' and more generally being the scapegoat of staff and resource shortages). The latter would lead to NHS difficulties in retaining staff. In addition, one can point to cultural constraints and experiences of discrimination which may discourage staff from staying in the UK (Young et al., 2010). These types of restrictions are likely to exert an independent effect even when legal restrictions are lifted. This may have far reaching consequences on hiring highly skilled professionals because often they cannot be easily substituted by nationals (it takes seven years to train new doctors and there is no guarantee that they will stay in the country. In contrast, hiring EU doctors comes at no major training cost, and guarantees comparable quality of care). So far, early figures from the Royal College of Nursing (2017) indicate that 2,700 EU nurses left the health service in 2016, compared to 1,600 in 2014 representing overall a 68 per cent increase.

An important reduction in the UK's attractiveness to employees lies in the reduced role of research as part of the job description for doctors which, unless Britain participates in EU programmes, will rely on national funding only. Furthermore, limits to the free movement of researchers across Europe are likely to affect the collaboration of UK researchers with European counterparts (Ghosh, 2016). To grasp an idea of the effects, one could look to Switzerland where the reduction of immigration from the EU led to a 40 per cent reduction in research funding (McKee and Galsworthy, 2016).

\section{Effects on wages}

One of the potential effects of Brexit will be on wages. Although evidence indicates that the areas of the UK with large increases in EU immigration did not experience a decline of employment and wages of UK-born workers (Wadsworth et al., 2015), Dustmann et al. (2013) found that immigration is associated with wage losses for those in the bottom 10 per cent of the pay distribution and larger wage gains for those in the middle. More precisely, estimates imply that the wave of EU immigration between 2004 and 2015 reduced wages in the bottom decile by 1 per cent, and overall increased wages for the median workers by 1.2 per cent. Hence, the expansion of EU immigration led to only marginally lower wages at the bottom decile alone, but not at the top. However, reducing EU immigration 
would then increase wages on both ends of the wage distribution due to increasing job vacancies at current wages. In such a scenario, the options available include incentivising EU immigration or expanding the health and social care spending in an attempt to transform it into a higher-wage sector, by increasing its productivity (Sumption, 2017). Hence, the trade-off is between saving on NHS funding by hiring health professionals from overseas, or expanding health investment further to incentivise local recruits (and solve the problem of chronic underfunding).

\section{Working Time Directive}

Leaving the EU may provide an opportunity to overcome the contentious application of the European Working Time Directive (WTD) which limits the maximum amount of time that employees in any sector can work to 48 hours each week (alongside rest periods and annual leave). Although abandoning the WTD might increase the flexibility in the labour market for health professionals, it will entail the imposition of tougher working conditions (Sheldon, 2004; Greer, 2008, Greer and Vanherecke, 2010). The WTD was put in place to harmonise labour standards across the EU and minimise the risk of 'social dumping'. Hence, lifting working time limits is likely to cause a deterioration in the quality of NHS employment and make working for the NHS less attractive. Specifically, the Royal College of Nursing (2017) has drawn attention to the importance of keeping the WTD to 'reduce fatigue' which can stand out as a risk to patients. In other words, Brexit opens the door to hardening the working conditions of NHS employees, at the 'critical moment' of fiscal consolidation. The latter can only lead to a deterioration in quality.

\section{Effects on patients}

Alongside its effects on the functioning of the labour market, Brexit has important implications for cross-border health care, which has historically enabled health care providers to send patients abroad for treatment provided prior authorisation had been granted ${ }^{9}$. Indeed, the Kohll and Decker procedure grants patients freedom to choose a provider abroad without prior authorisation from their home country (which includes the added entitlement to reimbursement from their national health care system under their home arrangements and costs). Hence, actual (or even potential) patient mobility gives rise to an incentive to seek for higher quality and/or cheaper treatments abroad, and subsequently apply for reimbursement without affecting significantly the utilisation and quality of care at both ends ${ }^{10}$. The overall impact of patient mobility on the NHS has, so far, been limited in magnitude. However, its reduction encompasses important restrictions in the use of potential health care which may have detrimental welfare consequences.

Rosenmöller et al. (2006) distinguish a number of scenarios where patients can benefit from patient mobility, which we reduce here to three. First, one 
might consider care to British citizens retiring to an EU country and hence wishing to use health care in the country of retirement. The UK in 2013 paid $\mathfrak{E} 805$ million to EEA countries, the majority of which was for UK state pensioners living in other EEA countries (Cabinet Office, 2013). Hence, leaving the EU entails additional transaction costs to set up a number of specific reciprocal cross-country agreements to guarantee access to health care for British retirees ${ }^{11}$. Second, some patients might take advantage of EU legislation to overcome capacity restrictions in the NHS. A survey conducted in 2007 found that many more people may be willing to travel for care within the EU than currently do so: over half ( 53 per cent) of all EU respondents to the European Commission survey, including 54 per cent of UK respondents, said they would be willing to travel to another EU country to seek medical treatment (The Gallup Organization, 2008). Hence, in this instance, cross-border mobility is a potential mechanism to reduce bottlenecks in the NHS which would not be available after Brexit. Finally, crossborder care can emerge when patients try to take advantage of treatments that are not available in the UK (e.g. a special medical treatment requiring high technology equipment), or that have been delisted for reimbursement in Britain. For instance, cancer patients who, having asked to pay privately for expensive anticancer drugs, do not manage to secure funding (Dawson and Mountford, 2008).

After Brexit, UK citizens face a more restricted set of choices over health care treatments. The only advantage, from a welfare perspective, of restricting mobility is that discouraging mobility reduces competition between health systems, and hence it could be argued that it deters a 'race to the bottom' in health care investment from taking place. However, given that patients are rarely asked to pay for health care in most European countries, and mobility is mostly not the result of waiting lists (a ruling by the European Court of Justice in 2006 found that compliance with a national waiting time target is not in itself sufficient to demonstrate that a patient is not experiencing undue delay in receiving care), such a race to the bottom does not seem to be taking place (judging from actual mobility). If it does, it may be driven by a search for better quality of care rather than lower costs. In contrast, restricting patient mobility after Brexit entails setting up additional controls at the point of access to health care which, inevitably, encompasses a change in the traditional conception of 'free care at the point of use'. These open the 'pandora box' for entitlement changes.

Finally, unless it is negotiated otherwise, British tourists might be excluded from the European Health Insurance Card (EHIC) programme, which provides free emergency care. So far, the average use of health services by immigrants and visitors appears to be lower than that of people born in the United Kingdom, which may be partly due to the fact that immigrants and visitors are, on average, younger (Steventon and Bardsley, 2011). Overall, Department of Health data show that it cost $\mathfrak{E}_{30 \mathrm{~m}}$ in $2013-14$ to meet the costs of European visitors using the NHS. This is less than one-fifth of the $\mathfrak{E} 155 \mathrm{~m}$ NHS cost faced by other states 
in the European single market for treating ill British tourists. Hence, the UK will experience a net loss from losing the existing reciprocal access to health care. Already, the UK introduction of a $\mathfrak{E} 200$-a-year health 'surcharge' for all new

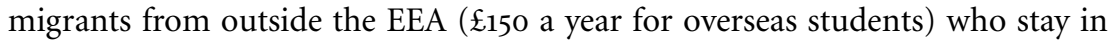
the UK for longer than six months has been proposed, and such a surcharge is payable upfront and covers migrants for the duration of their visa.

Finally, leaving the EU entails foregoing the efficiency gains from running global public services at a larger European scale unless the UK decides to join those specific programmes such as the European Centre for Disease Control (ECDC). Again, the effect results in higher costs to the British taxpayer mainly from forgoing economies of scales from participation in EU programs.

\section{Conclusion}

From a historical standpoint, major health systems reforms in the UK have traditionally been attributed to 'accidents of history' in critical moments (Tuohy, 1999). This paper has argued that Brexit is a 'critical moment' for the NHS. Specifically, we argue that, in all certainty, it will entail a cost increase associated with a rise in the costs of intermediary inputs, especially labour costs, to attract qualified staff alongside other inputs affected by non-tariff barriers (e.g. rules of origin checks, regulatory barriers, border controls etc). This takes place in the midst of a process of fiscal consolidation (leading to longer waiting lists, waiting times etc) which creates additional financial pressures for more substantial and transformative policy reform. However, whether it gives rise to a 'critical juncture' will largely depend on the exact Brexit deal, the contradictions in the health policy debate and, specifically, how the UK solves the aforementioned qualitycost conundrum. If publicly funded provision of health care is costlier to the British public, and there is no appetite for further tax increases, Brexit might entail spending cuts. If NHS quality deteriorates as a result of spending cuts, some share of the population might well take up private health insurance and reduce their support for further NHS improvements in quality (Costa-Font and Jofre-Bonet, 2008; Costa-Font and Garcia, 2003). However, if there is a way to inject further resources into the NHS (e.g. earmarked tax on health), the latter can be prevented.

In any event, the introduction of restrictions to patient mobility will inevitably entail a redefinition of the traditional values of 'free access at the point of use' which are largely supported by 89 per cent of the British public ${ }^{12}$, and may operate as 'small events' to introduce restrictions to health care entitlements. In addition, charges for emergency care can have knock-on effects on the health of asylum seekers and refugees entering Britain. Nonetheless, whether the status quo prevails or not will depend on the power and influence of key health system stakeholders (e.g. medical profession, trade unions etc) and, particularly, their capacity to confront pressures for an increased role for the private sector. That is, whether or not 
they are able to tilt the balance of the quality-cost conundrum back into relaxing fiscal pressures so as to maintain the traditional quality standards. Given that Brexit reduces the existing constraints on employment quality (if the WTD is not implemented) alongside 'equality and patient choice' (if EU legislation is not implemented), it is unlikely to render further improvements in efficiency and equity.

Nonetheless, Brexit brings some opportunities too, including the possibility of redefining the NHS in new directions. It might prevent or reduce a hypothetical future 'race to the bottom' (a reduction in health entitlements from cross-country health system competition) in health care services if it ever developed. However, so far evidence of such a race to the bottom has not been substantiated (CostaFont et al., 2015). Furthermore, given that health care is a devolved responsibility in the UK, it is likely that it will exhibit different effects in different countries of the UK, and especially in Scotland and Northern Ireland if they remain part of the UK. This might exacerbate the existing diversity between the different models of health care devolution in the UK (Greer, 2010). Hence, as hypothesized in this paper's title, Brexit, or a version of it, will mean hectic times for the NHS.

\section{Acknowledgements}

I am grateful for the comments of the two referees and the editors, as well as Riccardo Maestri and the participants of the European Institute seminar Europe @ LSE, and specifically Kevin Featherstone, Vassilis Monstoriotis, Steve Coulter, Chrysoula Papalexatou as well as other participants for their suggestions and criticisms. I am solely responsible for any errors and the usual disclaimer applies.

\section{Notes}

1 This compares to other estimates on the effects of foregoing EU membership which range between 8.6 and 10.6 per cent (Crafts, 2016)

2 The UK will not benefit from the 2018 harmonization process taking place within the EU which implies losing out on some important clinical trials that might otherwise benefit patients as the country would no longer be part of the harmonized procedure (King's Fund, 2016). There are some other restrictions to mention, namely, the UK and the EU would be required to maintain separate databases on pharmaceutical products in the market, and the move of the European Medicines Agency (EMA) out of London will erode some proximity advantages. The UK will not enjoy access to a single application to licence and authorise a new product. This will result in higher costs.

3 The Observer newspaper (March 18) quoted a paradigmatic example of a Spanish nurse stating: 'Since Brexit, I feel like a second-class citizen. My son asked me if I was going to be forced back to Spain and my daughter doesn't want to visit her grandparents because she fears I will not be able to come back'. See: https://www.theguardian.com/society/2017/ mar/18/nhs-eu-nurses-quit-record-numbers

4 Under the OMC, the Council of Ministers decides upon a common set of goals and each Member State then develops a national action plan which includes guidelines, timetables and indicators.

5 That is, country-specific economic recommendations and fiscal adjustment programs (Azzopardi-Muscat et al., 2015). 
6 For instance, some argue that without the EU, it is unlikely that UK advocates would have resisted the pressure of tobacco industry lobbies in banning tobacco advertising (McKee and Galsworthy, 2016).

7 Similarly, Baker (2016) finds important differences in the presence of EU health care staff across the country, and specifically, finds a higher concentration in London (15 per cent of all staff).

8 This is an important point considering that the UK had to introduce several exemptions affecting nurses and midwives Tier 2 immigration salary thresholds.

9 In other words, prior authorisation was an essential constituent of cross-border patient mobility. Regulation 1408/71 in the early 1970 (later supplanted by Regulation 574/72) held that if a right to cross-border care exists, it is the responsibility of the appropriate institution in the competent state to pay for it, and if permission to receive treatment abroad is granted, this must be through the issue of an E112 form (in practice, member states would be reluctant to allow this if the necessary treatment could be provided at home).

10 Wadsworth (2013) finds no greater usage of doctors and hospitals by non-UK born in the UK and Giuntella et al. (2015) find barely no effect on NHS waiting times.

11 To date, there are about 1.2 million British migrants living in other EU countries, compared with around 3 million EU migrants living in the UK (Hawkins, 2016).

12 Indeed, the majority of the British population ( 89 per cent) agrees that the government should support a national health system that is tax funded (British Social Attitude survey, 2014).

\section{References}

Addicott, R., Maguire, D., Honeyman, M. and Jabbal, J. (2015), Workforce planning in the NHS, London: The King's Fund.

Aiken, L. and Buchan, J. (2004), 'Trends in international nurse migration', Health Affairs, 2004, $23(3) 69$

Azzopardi-Muscat, N., Clemens, T., Stoner, D. and Brand, H. (2015), 'EU Country Specific Recommendations for health systems in the European Semester process: Trends, discourse and predictors', Health Policy, 119(3), 375-383.

Ballard, K. and Laurence, P. (2004), 'An induction programme for European GPs coming to work in England: development and evaluation', Education for Primary Care 15, 584-95

Baker, C. (2016), NHS staff from overseas: statistics, House of Commons Briefing Paper, 7783, 25 November.

Blitz, B. (2005), ' 'Brain circulation': the Spanish medical profession and international medical recruitment in the UK', Journal of European Social Policy 15 (4) 363-36

Buchan, J., Seccombe, I. and Charlesworth, A. (2016), Staffing matters; funding counts'. Workforce profile and trends in the English NHS, Health Foundation, London, UK.

British Social Attitudes (2014). British Social Attitude Survey, NatCen, available at http://natcen.ac.uk/our-research/research/british-social-attitudes/

Capoccia, G. and Kelemen, R. D. (2007), 'The Study of Critical Junctures: Theory, Narrative, and Counterfactuals in Institutional Analysis ', World Politics 59 (3):341-69

Crafts, N. (2016), The Growth Effects of EU Membership for the UK: a Review of the Evidence. University of Warwick CAGE Working Paper, (280).

Costa-Font, J. and Garcia, J. (2003), 'Demand for private health insurance: how important is the quality gap?' ,Health Economics, 12 (7). 587-599.

Costa-Font, J. and Jofre-Bonet, M. (2008), 'Is there a 'secession of the wealthy'?: private health insurance uptake and National Health System support', Bulletin of Economic Research, 60 (3). 265-287

Costa-Font, J., De-Albuquerque, F. and Doucouliagos, H. (2015), 'When does interjurisdictional competition engender a 'race to the bottom'? A meta-regression analysis', Economics \& Politics , 27 (3). 488-508 
Dawson, D. and Mountford, L. (2008), Health care services and the single European market, OHE Briefing, (44).

Dunn, P., McKenna, H. and Murray, R. (2016), 'Deficits in the NHS 2016'. Kings Fund, London.

Francis, R. (2013), The Mid Staffordshire NHS Foundation Trust Public Enquiry, London: The Stationery Office.

Foot, C., Sonola, L., Bennett, L., Fitzsimons, B., Raleigh, V. and Gregory, S. (2014), Managing quality in community health care services, London: The King's Fund.

Ghosh, P. (2016), 'Paul Nurse: “Research needs free movement to thrive', BBC website. Available at:www.bbc.co.uk/news/science-environment-36667987 (accessed September 2016).

Giuntella, O., Nicodemo, C. and Vargas Silva, C. (2015), 'The Effects of Immigration on NHS Waiting Times', University of Oxford Working Paper.

Greer, S. and Vanhercke, B. (2010), Health Care and the EU: The Hard Politics of Soft Law. In Health Systems Governance in Europe: The Role of EU Law and Policy, eds. R. Baeten, T. K. Hervey, E. Mossialos and G. Permanand. Oxford: Oxford University Press

Greer, S. L. (2008), 'Choosing paths in European Union health services policy: a political analysis of a critical' juncture, Journal of European Social Policy, 18(3), 219-231.

Greer, S.L. (2010), 'How does decentralization affect the welfare state?', Journal of Social Policy 39(2): 181-201

Lafond, S., Arora, S., Charlesworth, A. and McKeon, A. (2014), Into the red? The state of the NHS' finances: an analysis of NHS expenditure between 2010 and 2014. London: Nuffield Trust.

McKee, M. and Galsworthy, M. J. (2016), 'Brexit: a confused concept that threatens public health', Journal of Public Health, 38(1), 3-5

Mossialos, E., Simpkin, V., Keown, O. and Darzi, A. (2016), Will the NHS be affected by leaving or remaining in the EU? Briefing. LSE website. Available at: www.lse.ac.uk/newsAndMedia/ news/archives/2016/06/Leaving-the-EU-poses-critical-threat-to-NHS.aspx (accessed September 2016)

NHS Employers (2015), NHS Registered Nurse Supply and Demand Survey. NHS Employers, 2015. www.nhsemployers.org/case-studies-and-resources/2016/o1/2015-nhsregistered-nurse-supply-and-demandsurvey-findings

Rosenmöller, M., McKee, M. and Baeten, R. (2006), Patient mobility in the European Union: learning from experience, London: European Observatory on Health Systems and Policies, Brussels.

Royal College of Nursing (2017), Nursing priorities for the United Kingdom's withdrawal from the European Union. March. Accessed March 2017 in: file:///Users/costafon/Downloads/BR-1116.pdf

Royal College of Physistians (2017), NHS reality check Delivering care under pressure. March. Accessed March 2017: https://www.nursingtimes.net/download?ac $=3027179$

Sheldon, T. (2004), 'Pressure Mounts over European Working Time Directive', British Medical Journal 328 (17 April): 911.

Steventon, A., Bardsley, M. (2011). Use of secondary care in england by international immigrants. Journal of health services research \& policy 16(2), 90-94.

Tuohy, C.H. (1999), Accidental Logics: the Dynamics of Change in the Health Care Arena in the United States, Britain and Canada, New York: Oxford University Press.

Van Reenen, J. (2016), 'Brexit's Long Run Effects on the UK Economy', Brooking Papers of Economic Activity, Fall, 367-383.

Wadsworth, J. (2013), 'Mustn't Grumble: Immigration, Health and Health Service Use in the UK and Germany', Fiscal Studies 34(1): 55-82

Wadsworth, J., Dhingra, S., Ottaviano, G. and Van Reenen, J. (2015), 'Brexit and the Impact of Immigration on the UK', CEP Paper Brexit.

Young, R., Weir, H. and Buchan, J. (2010), Health professional mobility in Europe and the UK: a scoping study of issues and evidence. London: The National Coordinating Centre for the Service Delivery and Organisation. 